\title{
XXIII. The distribution of heat in the visible spectrum
}

\section{Sir John Conroy Bart. M.A.}

To cite this article: Sir John Conroy Bart. M.A. (1879) XXIII. The distribution of heat in the visible spectrum , Philosophical Magazine Series 5, 8:48, 203-209, DOI: $10.1080 / 14786447908639672$

To link to this article: http://dx.doi.org/10.1080/14786447908639672

曲 Published online: 13 May 2009.

Submit your article to this journal ¿

Џ Article views: 3

Q View related articles ¿ 
of the atomic theory. A modified form of Berthollet's assertion that the affinity of an acid is greatest for that base with which it combines in smallest quantity, seems to be suggested by Thomsen's results (confirmed by Ostwald's volumetric method) that large affinity-value is accompanied by low heat of neutralization.

Ostwald furnishes chemistry with a new method for solving some of her most difficult problems ; and Guldberg and Waage lead the way in the application of mathematical reasoning to the facts of chemical science.

XXIII. The Distribution of Heat in the Visible Spectrum. $B y$ Sir John Conroy, Bart., M.A.*

TN a paper "On the Distribution of Heat in the Spectrum," 1 originally published in the Philosophical Magazine for August 1872, and since reprinted in a volume of 'Scientific Memoirs,' Dr. J. W. Draper states the theoretical reasons for supposing that all the rays in the spectrum have the same heating effect, in the following words:- "A given series of waves " of red light impinging upon an extinguishing surface will produce a definite amount of heat; and a similar series of violet waves should produce the same amount; for though an undulation of the latter may have only half the length of one of the former, and therefore only half its vis viva, yet in consequence of the equal velocity of waves of every colour, the impacts or impulses of the violet series will be twice as frequent as those of the red. The same principle applies to any intermediate colour; and hence it follows that every colour ought to have the same heating effect."

Dr. Draper gives an account of some expcriments he has made on the distribution of heat in the visible spectrum of sunlight. Ho finds that if the visible spectrum betworn $A$ and $\vec{H}_{2}$ be divided into two equal portions, and all the light of wave-lengths between 7604 and 5768 be collected togetler, and also all that of ware-lengths between 5768 and 3933, the heat-intensity of these two series of undulations as determined by the thermopile are equal.

The distribution of heat in the spectrum of sunlight had been previously experimentally investigated by Sir W. Herschel (Phil. Trans. 1800, p. 255), J. Müller (P̈ogg. Ann. cv.

* Communicated by the Physical Society, having been read at the Meeting held on June 28. 
p. 337), Franz (Pogg. Ann. cxv. p. 266), Knoblauch (Pogg. Ann. exx. p. 177, and exxxvi. p. 66), Fizeau and Foucault (Comptes Rendus, xxv. p. 447, and reprinted in the Annales de Chimie, 5th series, xv. p. 363), Desains (Comptes Rendus, lxvii. p. 297, and lxx. p. 985), Lamansky (Pogg. Ann. cxlvi. p. 200). Similar measurements were made with the limelight by Desains (loc. cit.) and Lamansky (loc. cit), and of the electric light by Professor Tyndall (Phil. Trans. 1866, p. 1). They all found but slight indications of heat in the violet and blue regions of the spectrum, the amount increasing in the green, yellow, and red, and attaining a maximum at a point beyond the end of the visible spectrum.

The experiments were all made by placing a thermometer (one of the ordinary construction being used by Sir W. Herschel and MM. Fizeau and Foucault, and a thermopile and galvanometer by the other observers) in various parts of the dispersion-spectrum formed by prisms of either glass, rock-salt, or sylvine. As Dr. Draper points out in the paper already referred to, this method appears to be an essentially defective one, as, owing to the unequal dispersion by the prism of rays of different refrangibility, a greater number of undulations of different wave-lengths must have been incident upon the surface of the thermometer when it was placed in the red and yellow portions of the spectrum than when placed in the green, blue, or violet portions; and the amount of heat indicated by the instrument being in proportion to the amount of radiant energy incident upon its surface, the unequal dispersion of the prism would be sufficient to account for some difference in the heating effects produced by different portions of the spectrum

A graphical method appearing to afford the readiest means of determining the probable effect produced by the unequal dispersion of the prism, a tracing was made, on paper divided into squares of $\frac{1}{10}$ inch, of the curve representing the intensity of the heat in different portions of the visible spectrum, as determined by MM. Fizeau and Foucault (Ann. de Chim. 5 sér. xv. p. 377)-the position of the fixed lines in the spectrum, as given by them, being marked on one edge of the paper, which was taken as the $x$ axis, and a scale of wave-lengths in "tenthmetres" laid down at right angles to this, and the curve for the dispersion of the prism constructed in the ordinary manner. At nineteen equidistant points in the spectrum the ordinates of the dispersion-curve were measured in wave-lengths; the difference between any two of them gave, approximately, the dispersion of the prism for that portion of the spectrum. A 
difference of wave-length of 100 was taken as the unit, and the difference between the values of the ordinates divided by 100 considered as a measure of the dispersion. The ordinates

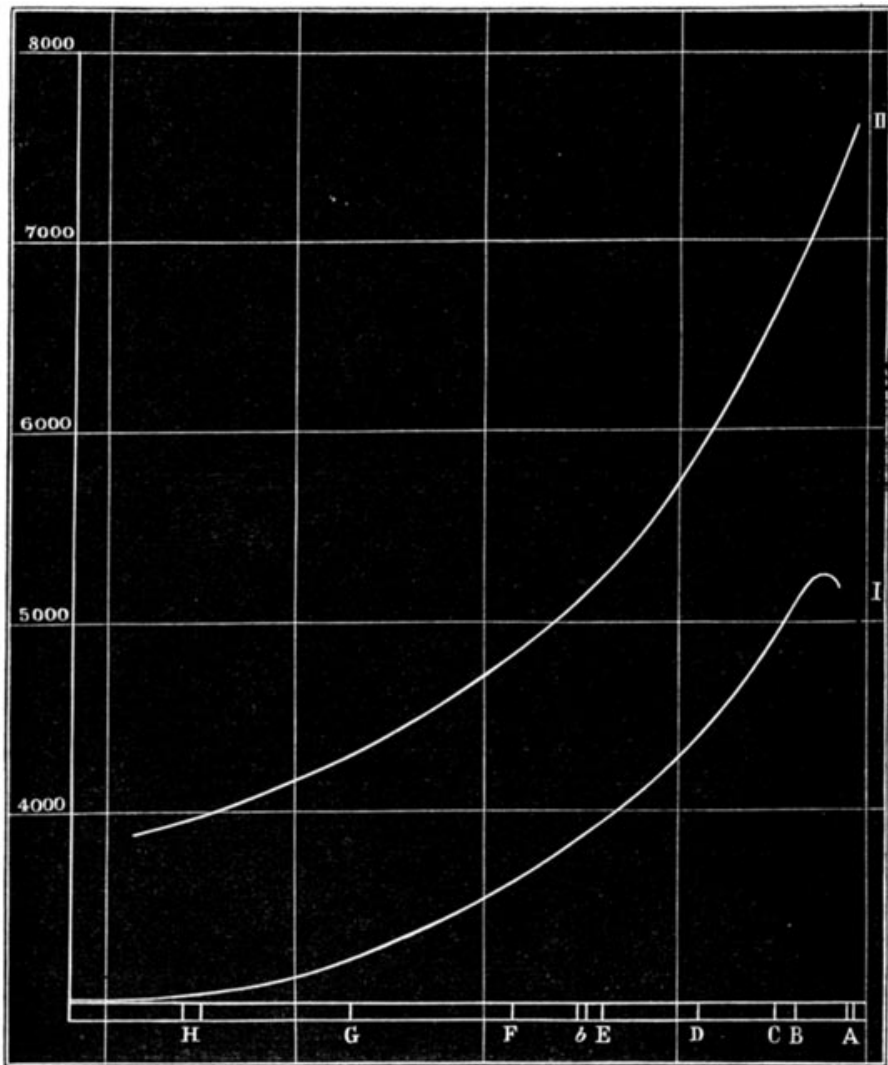

of the heat-curve of MM. Fizeau and Foucault at eighteen points in the spectrum, midway between those at which the ordinates of the dispersion-curve had been taken, were measured in tenths of an inch, these numbers divided by those representing the dispersive power of the prism, and the quotients taken as giving the true relative intensity of the heat at the different points of the spectrum. 
Sir John Conroy on the Distribution

\begin{tabular}{|c|c|c|c|}
\hline $\begin{array}{l}\text { Ordinates of } \\
\text { the disper- } \\
\text { sion-curve. }\end{array}$ & $\begin{array}{l}\text { Difference } \\
\text { divided by } 100 \\
(\alpha) .\end{array}$ & $\begin{array}{c}\text { Ordinates of } \\
\text { the heat-curre } \\
(\beta) .\end{array}$ & $\frac{\beta}{\alpha}$. \\
\hline $\begin{array}{l}7260 \\
6790 \\
6320 \\
6000 \\
5750 \\
5500 \\
5260 \\
5070 \\
4900 \\
4750 \\
4610 \\
4490 \\
4380 \\
4270 \\
4170 \\
4070 \\
4000 \\
3930 \\
3880\end{array}$ & $\begin{array}{l}4 \cdot 70 \\
4 \cdot 70 \\
3 \cdot 20 \\
2 \cdot 50 \\
2 \cdot 50 \\
2 \cdot 40 \\
1 \cdot 90 \\
1 \cdot 70 \\
1 \cdot 50 \\
1 \cdot 40 \\
1 \cdot 20 \\
1 \cdot 10 \\
1 \cdot 10 \\
1 \cdot 00 \\
1 \cdot 00 \\
\cdot 70 \\
\cdot 70 \\
\cdot 50\end{array}$ & $\begin{array}{r}22 \cdot 4 \\
19 \cdot 0 \\
15 \cdot 9 \\
13 \cdot 7 \\
11 \cdot 8 \\
10 \cdot 3 \\
8 \cdot 8 \\
7 \cdot 5 \\
6 \cdot 2 \\
5 \cdot 0 \\
4 \cdot 0 \\
3 \cdot 3 \\
2 \cdot 5 \\
1 \cdot 8 \\
1 \cdot 3 \\
1 \cdot 0 \\
\cdot 7 \\
\cdot 5\end{array}$ & $\begin{array}{l}4 \cdot 7-\mathrm{B} . \\
4 \cdot 0-\mathrm{C} . \\
5 \cdot 0 \\
5 \cdot 5-\mathrm{D} . \\
4 \cdot 7 \\
4 \cdot 3-\mathrm{E} . \\
4 \cdot 6--b . \\
4 \cdot 4-\mathrm{F} . \\
4 \cdot 1 \\
3 \cdot 5 \\
3 \cdot 3 \\
3 \cdot 0 \\
2 \cdot 2-\mathrm{G} . \\
1 \cdot 8 \\
1 \cdot 3 \\
1 \cdot 4 \\
1 \cdot 0-\mathrm{H} . \\
1 \cdot 0\end{array}$ \\
\hline
\end{tabular}

The Table shows that the numbers thus obtained for the intensity of the heat in different portions of the spectrum lie close together for the region between $B$ and $F$, the maximum being near $\mathrm{D}$, and that from $\mathrm{F}$ to $\mathrm{H}$ the intensity diminishes.

It would further appear that the curve for the distribution of heat of MM. Fizeau and Foucault is in reality a dispersioncurve, drawn to some scale of wave-lengths, for the particular prism used by them; and the diagram show's how very similar the curves for the intensity of the heat, and for the dispersion of the prism are to one another.

The heat-curve reaches the $x$ axis at a short distance on the more refrangible side of $\mathrm{H}_{2}$, the wave-length of that line being 3932. The axis was taken as 3900 on the scale of wave-lengths to which the curve is drawn, and therefore the ordinate of the curve at $\mathrm{B}$, measured in tenths of an inch, as proportional to the difference between this number and the wave-length of $B$, and the height of the ordinates at the other lines calculated on this assumption.

\begin{tabular}{|c|c|c|c|}
\hline B & $\begin{array}{l}\text { Measured, } \\
\text {........ } 2 \cdot 10\end{array}$ & Calculated. & Difference. \\
\hline $\mathrm{C}$ & $\ldots \ldots \ldots . .1 \cdot 87$ & $1 \cdot 88$ & $+\cdot 01$ \\
\hline D & ......... 1 $1 \cdot 34$ & $1 \cdot 41$ & .07 \\
\hline $\mathrm{E}$ & ........ $\cdot 95$ & .97 & $\cdot 02$ \\
\hline$b$ & $\ldots .88$ & .90 & $\cdot 02$ \\
\hline $\mathbf{F}^{\mathrm{r}}$ & $\ldots \ldots \ldots$ & 68 & $\cdot 05$ \\
\hline$G$ & ........ $\cdot 22$ & .29 & $\cdot 07$ \\
\hline
\end{tabular}


Considering the nature of the data, and especially the small scale of MM. Fizeau and Foucault's diagram (the portion representing the visible spectrum being only about 4 inches long), the measured and calculated numbers agree fairly well together.

The same process was applied to the curves given by Lamansky (Pogg. Ann. cxlvi. p. 200) for the distribution of heat in the solar spectrum, with flint-glass and rock-salt prisms.

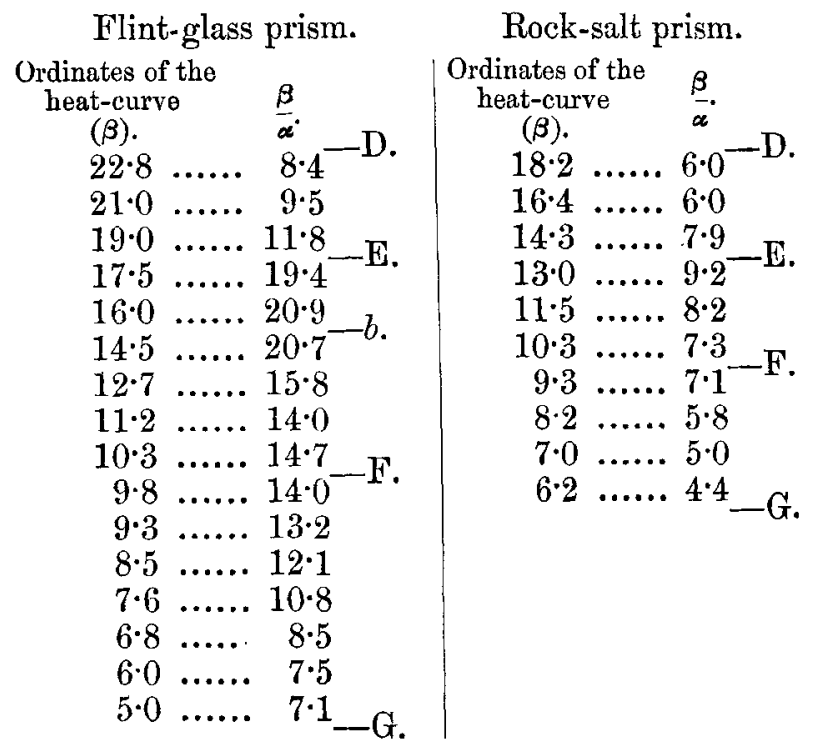

Assuming the curves to be the dispersion-curves for the prisms, the ordinates were measured and calculated as in the former case.

Flint-glass prism.

Measured. Calculated.

D ...... $23 \cdot 6$

E $\ldots \ldots . .17 \cdot 8$

$b \quad \ldots . . .15 \cdot 4$

F ...... $10 \cdot 2$

G $\ldots . . .4 \cdot 4 \cdot 0$
Rock-salt prism.

Measured. Calculated.

D ....., 18:3

E $\ldots . . .13 \cdot 7 \quad 13 \cdot 4$

F $\ldots . . . .9 \cdot 8 \quad 10 \cdot 3$

G ...... $6 \cdot 0$

In none of the other measurements that have been made of the heat-spectra, as far as I am aware, are the positions of the solar lines stated; and therefore part of the data for eliminating the action of the unequal dispersion of the prisms is wanting.

An attempt was made to deal with Knoblauch's measure- 
ments of the solar spectrum, and with Tyndall's of that of the electric light, by the same method.

In both cases the experiments were made with rock-salt prisms; and these were assumed to have the same dispersive power as the one used by Lamansky, and the curve plotted accordingly. Two sets of measurements are given by Knoblauch; and the mean of these was taken for the following calculations.

Knoblauch's measurements.

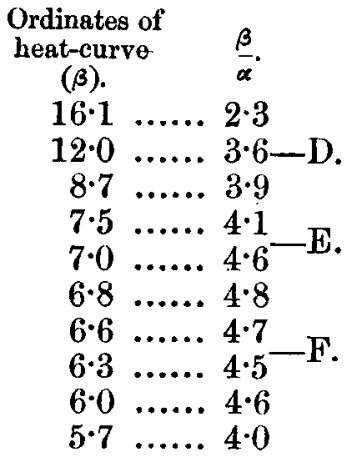

Tyndall's measurements.

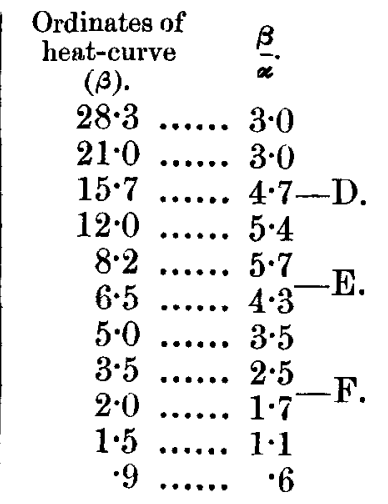

The nature of the available data is such that the only definite conclusions which it is possible to draw from these calculations are, that the distribution of heat in the normal spectrum differs greatly from that in the dispersion-spectrum, and that in the dispersion-spectrum the great calorific intensity of the red rays, and therefore in all probability of the invisible rays beyond them, is due to the action of the prism in concentrating these rays upon the face of the thermopile. The intensity of the heat in the different portions of the normal spectrum, except in the case of Lamansky's measurements with the flintglass prism, apparently varies but little through a considerable space; and this affords some support to Dr. Draper's hypothesis, that every colour ought to have the same heating effect.

After I had finished these calculations, I found that G. Lundquist had investigated (Pogg. Ann. clv. p. 146), from Lamansky's measurements, the distribution of heat in the normal spectrum, and had shown that it differed greatly from the distribution in the dispersion-spectrum-the maximum intensity in the case of the flint-glass prism being near $\mathrm{D}$, and in the rock-salt prism near E. He also found from Tyndall's 
measurements of the heat of the electric-light spectrum, that in the normal spectrum the maximum was near $\mathrm{A}$.

Lundquist arrived at these results by a mathematical process, based on the same general principles as the graphical one I have employed.

XXIV. On Structures in an Earthquake Country. By JоHN Perrix and W. E. Ayrton, Professors in the Imporial College of Engineering, Japan*.

IN a country like Japan, where several sharp earthquakes 1 occur yearly, where there are between three and four hundred destructive earthquakes on record, and where over a hundred thousand people are said to have been killed in one almost continued earthquake lasting for a month, and which occurred so recently as 1855 , the question of the stability of structure is all-important.

When working at our paper "On a neglected Principle that may be employed in Earthquake Measurements," read before the Asiatic Society of Japan on the 23rd of May, 1877, and which appeared in the Number of the Philosophical Magazine for July 1879, we were led to consider how the effect produced by an earthquake on a structure is influenced by the time of vibration of the structure.

It follows from that principle that if a number of quickly vibrating bodies form part of the same structure, they all vibrate in much the same way; that is, the periods of their swings are all approximately equal to one another and equal to the periods of the earthquake; and although they differ in the amount of their motions, these amounts and their differences are all exceedingly small; whereas if one or more of the parts of the structure are only capable of vibrating slowly, the periods of vibration of the different parts vary very much, the amounts of the motions are all comparatively great, and theirdifferences are all relatively considerable. If, however, there is a sufficiently great viscous resistance to motion of such slowly vibrating parts, these parts will be found during an earthquake to behave much as if their natural periods of vibration were quick. Supposing the foundation of a structure to vibrate with the earth which encloses it, we see that a slowly vibrating structure which is fastened to these foundations is during an earthquake subjected to stresses which may be excessively great and of a very complicated kind, whereas a quickly vibrating structure is subjected to stresses which may be said to be do-

* Communicated by the Authors. 